\title{
Practical and Theoretical Study on the Inhibitory Influences of New Azomethine Derivatives Containing 8-hydroxyquinoline Moiety for the Corrosion of Carbon Steel in $1 \mathrm{M} \mathrm{HCl}$
}

\author{
A. EL YAKTINI ${ }^{1}$, A. LACHIRI ${ }^{1}$, M. EL FAYDY ${ }^{2}$, F. BENHIBA ${ }^{3}$, H. ZARROK ${ }^{3}$, M. EL AZZOUZI $^{4}$, \\ M. ZERTOUBI ${ }^{1}$, M. AZZI ${ }^{1}$, B. LAKHRISSI ${ }^{2}$ and A. ZARROUK ${ }^{5 *}$ \\ 'Laboratoire Interface Matériaux Environnement, Faculté des Sciences, Université Hassan II Casablanca, \\ B.P 5366 Maârif Casablanca Morocco. \\ 2Laboratory of Agricultural Resources, Polymer and Process Engineering, Department of Chemistry, Faculty \\ of Sciences, Ibn Tofail University, Kenitra, Morocco. \\ ${ }^{3}$ Laboratory of Separation Procedures, Faculty of Sciences, Ibn Tofail University, Kenitra, Box 133, \\ Kenitra, Morocco. \\ ${ }^{4}$ LC2AME, Faculty of Sciences, Mohammed First University, PO Box 717, 60000 Oujda, Morocco. \\ ${ }^{5}$ Laboratory of Materials, Nanotechnology and Environment, Faculty of Sciences, Mohammed V \\ University, Av. IbnBattouta, Box 1014 Agdal-Rabat, Morocco. \\ ${ }^{*}$ Corresponding author E-mail: azarrouk@gmail.com
}

http://dx.doi.org/10.13005/ojc/340643

Received: November 04, 2018; Accepted: November 15, 2018)

\begin{abstract}
The inhibition ability of a new Azomethine derivatives containing the 8-hydroxyquinoline (BDHQ and $\mathrm{MDHQ}$ ) towards carbon steel corrosion in $\mathrm{HCl}$ solution was studied at various concentrations and temperatures using weight loss, polarization curves and electrochemical impedance spectroscopy (EIS) methods. The experimental results reveal that BDHQ and MDHQ are efficient mixed type corrosion inhibitors, and their inhibition efficiencies increase with increasing concentration. The adsorption of these inhibitors on mild steel surface obeys Langmuir isotherm. Quantum chemical parameters are calculated using the Density Functional Theory method (DFT) and Monte Carlo simulations. Correlation between theoretical and experimental results is discussed.
\end{abstract}

Keywords: Synthesis, Carbon steel, Corrosion inhibition, Electrochemical techniques, DFT.

INTRODUCTION

Carbon steel is practically used in all the industrial sectors (bridges, railways, buildings, etc.) because of their admirable physical properties and low cost $^{1}$, their problem is that is easily corrodible in common environments of usage. In this context, in order to minimize the effect of corrosion, in this context, in order to minimize the effect of corrosion, several methods have been implemented such as:

This is an Open Access article licensed under a Creative Commons license: Attribution 4.0 International (CC- BY). Published by Oriental Scientific Publishing Company @ 2018

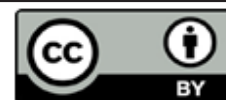


anodic or cathodic protection, surface coatings and corrosion inhibitors ${ }^{2-4}$, this latter method has become more practical because of its low cost, high efficiency and easily to use.

A lot of synthetic organic and inorganic molecules containing conjugated heterocycle, heteroatoms and electronegative functional groups are shown excellent inhibitory properties ${ }^{5-7}$, the electronrich groups can donate the lone pair of electrons to the electron deficient metal cations and consequently an adsorption on the metal surface by forming a coordinate covalent bond (chemical adsorption) or by forming a van-der-Waals interactions (physical adsorption) between the metal and inhibitor ${ }^{8,9}$.

Quinoleic heterocyclic compounds are among the classic divisions of organic chemistry which develops most quickly ${ }^{10}$. This discovery resulted in the synthesis of a large number of new compounds. So the introduction of novel heterocyclic functional groups into quinoline structures, for example, allowed the preparation of a wide variety of compounds ${ }^{11}$. We also find 8-Hydroxquinoline, which constituted by the juxtaposition of pyridine and phenol rings. It establishes the main structural moiety of a large number of molecules with pharmacological properties ${ }^{12,13}$, which have found their use in all therapeutic fields. With its unique proprieties, 8 -Hydroxyquinoline $(8-\mathrm{HQ})$ is very effective to synthesize a number of ionophores with good performance in environments aqueous or organic ${ }^{14}$, it is very famous as a monoprotic bidentate chelator used in fluorescent sensing of biological and environmentally important metal ions and in separation techniques. Recently, the utilization of 8-HQ as corrosion inhibitors for aluminum, magnesium alloy, copper and iron has been examined in neutral aqueous sodium chloride solution ${ }^{15-20}$, the analysis of the literature shows that only very limited studies have been realize out on the impact of 8-hydroxyquinoline derivatives on the corrosion behaviour of carbon steel in $\mathrm{HCl}$ electrolyte ${ }^{21}$.

Azomethines or Schiff's base are the ligands very used in the complexation chemistry, and employed as intermediates in organic synthesis ${ }^{22}$, they are also synthesized from the condensation of primary amines and aldehydes, ketones and carboxylic acids. the existing data showed that the protection efficiency of Azomethine is significantly higher in comparison with corresponding amines and carbonyl compounds due to the presence of an $-\mathrm{HC}=\mathrm{N}-$ group in the molecules ${ }^{23,24}$.

The objective of the present investigation is to study the corrosion inhibition of carbon steel in acidic medium using new compounds containing a 5-methyl-8 hydroxyquinoline motive (BDHQ and $\mathrm{MDHQ}$ ) and to propose a suitable mechanism for the inhibition using the weight loss, potentiodynamic polarization and electrochemical impedance spectroscopy measurements and the thermometric method at a temperature range of 298-328k. In addition to this, quantum chemical calculations were performed to add theoretical support to the experimental results.

\section{EXPERIMENTAL}

\section{Materials}

The ingredients of working electrode (carbon steel) and their pre-treatment methods have been formerly described, the same thing with regard to the corrosive mediums ${ }^{25}$. The BDHQ and $M D H Q$ were studied in a gap of concentration ranging from $10^{-3}$ to $10^{-6} \mathrm{M}$. The border of this interval are determined for each synthesized products by its solubility (for maximum concentration of azomethine derivatives) and by their low inhibiting properties (for the minimum concentration of azomethine derivatives), the Azomethine derivative were prepared in moderate yield ( $56 \%$ for BDHQ and $60 \%$ for MDHQ) by the condensation of 5-aminomethyl-8-hydroxyquinoline (1eq), aldehydes (1eq) and of triethylamine (1eq) in $20 \mathrm{~mL}$ of dried ethyl acetate was heated under stirring for 20 hours. After completion and cooling to room temperature, water (50 $\mathrm{mL}+10 \mathrm{ml}$ of sodium bisulfite) was subsequently added and the product extracted. The combined organic phases were combined, dried over anhydrous sodium sulfate, filtered and evaporated. The obtained residue was purified by column chromatography with hexane/ acetone $(8: 3$ to $1: 9 \mathrm{v} / \mathrm{v})$.<smiles>[R]c1ccc(/C=N\Cc2ccc(O)nc2)cc1</smiles>

$\begin{array}{ll}\text { R: } & \text { H } \\ \text { RCH } & \text { (BDHQ) }\end{array}$

Scheme 1. Chemical structure of BDHQ and MDHA 
Identification of the structure of the synthesized Schiff base was performed by, ${ }^{1} \mathrm{H}$ NMR, ${ }^{13} \mathrm{C}$ NMR spectroscopy and elemental analysis. Analysis calculated for $\mathrm{C}_{17} \mathrm{H}_{14} \mathrm{~N}_{2} \mathrm{O}$ : Calcd. C, 77.84; H, 5.38; N, 10.68\%; Found: C, 77.76; H, 5.29; N, $10.75 \%$. The ${ }^{1} \mathrm{H}$ NMR spectrum show signals of the aromatic protons in the range 6.9-8.94 ppm, the signals of the methylene protons appear at 4.83 $\mathrm{ppm}$, and those of the imine protons appear at 8.4 ppm and the ${ }^{13} \mathrm{C}$ NMR for the BDHQ exhibited the aromatic carbons in the range $111.32-152.74 \mathrm{ppm}$, while that of imine at $168.92 \mathrm{ppm}$ and those of methylene appear at $60.84 \mathrm{ppm}$.

Analysis calculated for $\mathrm{C}_{18} \mathrm{H}_{16} \mathrm{~N}_{2} \mathrm{O}_{2}$ : Calcd. C 73.95; H 5.52; N 9.58\%; Found: C, 73.86; H, 5.46; N, $9.64 \%$, the ${ }^{1} \mathrm{H}$ NMR spectrum of MDHQ show signals of the aromatic protons in the range 6.92-8.51 ppm, the signals of the methylene protons appear at 4.23 $\mathrm{ppm}$, those of the imine proton appear at $8.71 \mathrm{ppm}$ and those of methyl appear at $3.56 \mathrm{ppm}$ and the ${ }^{13} \mathrm{C}$ NMR for the BDHQ exhibited the aromatic carbons in the range $111.06-153.21 \mathrm{ppm}$, carbon of $\left(\mathrm{O}-\mathrm{CH}_{3}\right)$ appears at $53.07 \mathrm{ppm}$, that of the imine appears at $162.83 \mathrm{ppm}$ and that of methylene appear at $62.12 \mathrm{ppm}$.

All ${ }^{1} \mathrm{H}$ NMR, ${ }^{13} \mathrm{C}$ NMR spectra are attached in supplementary data.

\section{Apparatus and Methods}

NMR $\left({ }^{1} \mathrm{H}\right.$ and $\left.{ }^{13} \mathrm{C}\right)$ spectra were registered using Bruker Avance $(300 \mathrm{MHz})$. The advancing of the reaction was followed by Thin-Layer Chromatography (TLC) using silica gel 60 F254 (E. Merck) plates). Elemental analyses were carried out by Elementar $\mathrm{CHN}$ VarioMicro Cube analyser. The Gravimetric experiments have been realized have been realized pursuant to the standard method A.S.T.M. G1-03 described beforehand ${ }^{26}$. The substrates of dimension $4 \times 1.5 \times 0.05 \mathrm{~cm}^{3}$ were chosen for to perform the weight loss tests. In order to obtain the reproducible results, all Experiments were repeated four times for each concentration. However, the electrochemical studies were realized by means of an Autolab $400 \mathrm{ml}$ corrosion cell (CORR.CELL). To reach steady state potential, CS (carbon steel) electrode with a surface area of $1 \mathrm{~cm}^{2}$ as working electrode, a platinum (Pt) electrode as an auxiliary electrode, saturated calomel electrode (SCE) used as a reference electrode and a fine Luggin capillary was put near CS to decrease ohmic resistance were maintained throughout the period considered (30 min.) in a thermostat at $298 \mathrm{~K} \pm 2$. The Tafel polarization was carry out at a scan rate of $0.5 \mathrm{mV} / \mathrm{sec}$. Before each Tafel experiment, the carbon steel electrode was pre-polarised at $-800 \mathrm{mVSCE}$ for $10 \mathrm{~min}$. and thereafter the WE was allowed to corrode freely and its open circuit potential (OCP) was recorded as a function of time up to $1 / 2 \mathrm{~h}$, the time necessary to reach a quasi-stationary value for the open-circuit potential. The potentiodynamic Tafel measurements were scanned from cathodic to the anodic direction.

Impedance measurement were effectuate at the steady state potential (Eocp), with a frequency interval from $100 \mathrm{kHz}$ down to $10 \mathrm{mHz}$, utilizing a small amplitude signals $(10 \mathrm{mV})$.

Electrochemical measurements were made with a PGZ 100 monitored by a PC supported by the VoltaMaster4 Software, and the obtained Nyquist plots were fitted employing ZView 3.3 software (Scribner Associates).

\section{DFT calculations}

Geometric optimizations of studied inhibitors and calculations on quantum chemical study were done following the Gaussian 09 commercial software ${ }^{27}$. The B3LYP density-functional theory (DFT) was used to optimize the structures of pyrazolo-pyrimidine derivatives using the $6-311++G$ $(d, p)$ basis set ${ }^{28}$. The calculated quantum chemical descriptors (QCP) related to the inhibition efficiencies are the orbital energies $E_{\text {номо }}$ and ELUMO, energy gap $(\Delta \mathrm{E})=\left(\mathrm{E}_{\text {LUмо }}-\mathrm{E}_{\text {номо }}\right)$, dipole moment $(\mu)$, electronegativity $(\chi)$, global hardness $(\square)$ and the report of electron transferred $\left(\Delta \mathrm{N}_{110}\right)$. The global reactivity of the compounds tested is determined by the indices (QCP) using the following equations ${ }^{29-32}$.

$$
\begin{gathered}
\mathrm{h}_{i n h}=\frac{E_{L U M O}-E_{\text {HOMO }}}{2}=\frac{\Delta E_{g a p}}{2} \\
\mathrm{c}_{i n h}=-\frac{1}{2}\left(\mathrm{E}_{\text {HOMO }}+E_{L U M O}\right) \\
\Delta N_{110}=\frac{\mathrm{f}-\mathrm{c}_{i n h}}{2\left(\mathrm{~h}_{F e_{110}}+\mathrm{h}_{i n h}\right)}=\frac{\mathrm{f}-\mathrm{c}_{i n h}}{2 \mathrm{~h}_{i n h}}
\end{gathered}
$$

The value of $\Delta \mathrm{N}_{110}$ was determined by the introduction of the job function $(\phi)$, the latter is equal the $4.82 \mathrm{eV}$ in the lattice plane (110) of iron. 
In addition, the $\eta_{\mathrm{Fe}}$ is zero for IP(Ionization potential) $=\mathrm{EA}$ (Electronic affinity) which corresponds the metallic bulk ${ }^{33}$.

The study of the local reactivity of an inhibitory molecule is very important to determine the active sites of this molecule. For this, we used the Fukui function $f(\vec{r})$. The latter is the first derivative of the electronic density $\rho(\vec{r})$ by the number of electrons $(\mathrm{N})$ located in a constant external potentia field $v(\vec{r})^{34}$ :

$$
f(\vec{r})=\left(\frac{\partial \mathrm{r}(\vec{r})}{\partial N}\right)_{\mathrm{u}(\vec{r})}
$$

Using the method of finite differences, both types of function such as $f_{i}(\vec{r})^{+}$(for a nucleophilic attack) and $f_{i}(\vec{r})^{-}$(or an electrophilic attack) can be defined:

$$
\begin{aligned}
& f_{i}(\vec{r})^{+}=\mathrm{r}_{N+1}(\vec{r})-\mathrm{r}_{N}(\vec{r}) \\
& f_{i}(\vec{r})^{-}=\mathrm{r}_{N}(\vec{r})-\mathrm{r}_{N-1}(\vec{r})
\end{aligned}
$$

The values of the Fukui function $f_{i}(\vec{r})$ and $f_{i}(\vec{r})^{-}$of BDHQ and MDHQ compounds are calculated by the of Materials Studio 8 software from Biovia-Accelrys Inc., using a GGA exchangecorrelation functional in the $\mathrm{Dmol}^{3}$ module with the polarization function DNP.

\section{Monte Carlo simuations}

The interactions study of compounds BDHQ and $M D H Q$ and the metal surface of the iron of lattice plane (110) is realized by the Monte Carlo method ${ }^{35}$. To take into account all the reactions that are made in ${ }^{1} \mathrm{M}$ hydrochloric acid medium in the presence of the inhibitors studied. For it, we have established a system similar to that found in the experimental part. Indeed, in Monte Carlo (MC) simulations we were interested in studying the behavior of the system (Surface Fe (110) / compounds (BDHQ and $\mathrm{MDHQ})$ ) in an aggressive acid environment with 5 $\left(\mathrm{H}_{3} \mathrm{O}^{+}, \mathrm{Cl}^{-}\right)$and $500 \mathrm{H}_{2} \mathrm{O}$. To carry out this simulation of the $\mathrm{MC}$, we followed a calculation methodology. Molecular mechanics calculation was done using Forcite tools and adsorption Locator tools implanted in the Materials Studio 2016 software ${ }^{36}$. Before inserting our inhibitors into the simulation cell, these inhibitors are optimized to minimize their energies using a GGA exchange-correlation functional for
Generalized Gradient Approximation in the $\mathrm{Dmol}^{3}$ module with the polarization function DNP. On the other hand, the simulation box of iron consisted of a 6 floors of iron atoms split along the (110) plane in the simulation cell $(29.78 \AA 29.78 \AA / 30.13 \AA)$ with periodic boundary conditions. A super cell of $(13 \times 13)$ for increase the covering area of the Fe (110) was created and a vacuum of $19.30 \AA$ was mounted above the surface considered. The COMPASS force field ${ }^{37}$ was used to optimize the structure of all components of the studied system such as the tested inhibitors, the chlorine anion $\left(\mathrm{Cl}^{-}\right)$, the hydronium cation $\left(\mathrm{H}_{3} \mathrm{O}^{+}\right)$, the water molecule $\left(\mathrm{H}_{2} \mathrm{O}\right)$ and the iron surface. The simulations were performed under fine convergence conditions for energy of $10^{-4} \mathrm{Kcal}_{\text {. }} \mathrm{mol}^{-1}$, the force of $0.005 \mathrm{Kcal}^{\mathrm{mol}}{ }^{-1}$. $\AA$ and the shifting of 5.10-5 $\AA$-1. While each simulation went through 5 cycles at 50,000 steps per cycle.

\section{RESULTS AND DISCUSSION}

\section{Gravimetric tests}

The two synthesized compounds of azomethine are first evaluated by weight loss measurements at $298 \mathrm{~K}$ after $6 \mathrm{~h}$ of immersion. The corrosion rate (CR) and protection efficiency $\eta \mathrm{g}(\%)$ were established by virtue of the formulas 7 and $8^{38}$, respectively:

$$
\begin{aligned}
& C_{R}=\frac{G_{b}-G_{a}}{A t} \\
& \eta_{g}=\left(\frac{C_{R 0}-C_{R 1}}{C_{R 0}}\right) \times 100
\end{aligned}
$$

Where $G_{b}$ and $G_{a}$ represent the weight before and after immersion in the electrolyte, $\mathrm{C}_{\mathrm{R} 0}$ and $\mathrm{C}_{\mathrm{R} 1}$ describe the values of corrosion weight losses of CS in blank medium and inhibited solutions, respectively, $A$ the surface of $C S$ and $t$ is the immersion time (h).

The results of this study are summarized in Table 1. For both inhibitors, the corrosion rate and the inhibitory efficiency are presented for each concentration used.

Analysis of the results in Table 1 clearly shows that these compounds have good inhibitory properties of $\mathrm{CS}$ corrosion in ${ }^{1} \mathrm{M} \mathrm{HCl}$ media. We also find that the corrosion rate decreases while the protection efficiency increases with the inhibitor 
concentration, and reaches a maximum value of $98 \%, 88 \%$ at optimum concentration, respectively for $M D H Q, B D H Q$. The increase in inhibitory efficiency with concentration suggests that this inhibitor adsorbs more and more at the surface and covers the active sites of the metal surface and thus induces the formation of a barrier that reduces the reactivity of the metal ${ }^{39}$.

Table 1: Corrosion data acquired by gravimetric method at different concentrations of azomethine derivatives in hydrochloric acid medium

\begin{tabular}{lcccc}
\hline Medium & Conc $(\mathrm{M})$ & $\mathrm{CR}\left(\mathrm{mg} / \mathrm{cm}^{2} \mathrm{~h}\right)$ & $\eta(\%)$ & $\theta$ \\
\hline Blank & 1 & 0.750 & - & - \\
MDHQ & $10-3$ & 0.015 & 98 & 0.98 \\
& $10-4$ & 0.075 & 90 & 0.90 \\
& $10-5$ & 0.127 & 83 & 0.83 \\
& $10-6$ & 0.210 & 72 & 0.72 \\
BDHQ & $10-3$ & 0.090 & 88 & 0.88 \\
& $10-4$ & 0.187 & 75 & 0.75 \\
& $10-5$ & 0.255 & 66 & 0.66 \\
& $10-6$ & 0.375 & 50 & 0.50 \\
\hline
\end{tabular}

In acidic environment, a fraction of synthesized molecules is protonated because of heteroatoms (nitrogen and oxygen) and become cations (MDHQ- $\left.\mathrm{H}^{+}, \mathrm{BDHQ}-\mathrm{H}^{+}\right)$and therefore adsorb through electrostatic interactions with chloride $(\mathrm{Cl})$ ions. The other fraction (neutral form) could form bonds with the orbital $\mathrm{d}$ of iron atoms, causing the displacement of water molecules from the metal surface and $\mathrm{sp}^{2}$ electron pairs isolated $\mathrm{N}$ and $\mathrm{O}$ atoms and $\pi$-orbitals, blocking the active sites in the surface of the steel and thus reducing the rate of corrosion. The obtained difference in terms of inhibition between $B D H Q$ and $M D H Q$ originates from the presence of the radical $R$ focused on benzene at Para position, the presence on MDHQ an methoxy substituent $\left(-\mathrm{O}-\mathrm{CH}_{3}\right)$ in MDHQ which is classified as an electron donating group ( ${ }^{+} \mathrm{M}$, Mesomeric effect) breeds an increasing the delocalization of electron density on the benzene ring, rendering the molecule more stable and therefore gives higher protection efficiency for the metal than $\mathrm{BDHQ}^{40}$.

\section{Adsorption isotherm}

The techniques available for discover the nature of the interactions between organic and metallic species are adsorption isotherms ${ }^{41}$. In this context, the number of numbers of models can be used to evaluate the adsorption process of $\mathrm{BDHQ}$ and $\mathrm{MDHQ}$ at working electrode surface as:
Temkin, Frumkin and Langmuir; which are estimated according to the next equations ${ }^{42}$ :

$$
\begin{array}{ll}
\text { Temkin } & : e^{(-2 a \theta)}=b C_{o c} \\
\text { Frumkin } & : \theta(1-\theta)^{-1} e^{(-2 a \theta)}=b C_{o c} \\
\text { Langmuir } & : C_{o c} \times \theta^{-1}=K_{d}^{-1}+C_{o}
\end{array}
$$

Where $\theta$ defined as the fraction of surface covered, $\mathrm{Kd}$ the constant of adsorption reaction and $\mathrm{C}_{\mathrm{oc}}$ is the organic compounds concentration.

The existing data show that the best fit is attained with Langmuir's isotherm for monolayer adsorption, the $\theta$ values obtained from gravimetric measurements, are given by

$$
\theta=\frac{\eta_{g}}{100}
$$

For both inhibitors, the graph of $\mathrm{C}_{\mathrm{oc}} / \theta$ with respect to $C_{o c}$ exhibit a straight line (Fig.1) with linear coefficient $\left(R^{2}\right)$ close to one; involving that the adsorption of azomethine molecules on the CS is well adapted to the Langmuir adsorption isotherm.

The constant $K_{d}$ obtained by the extrapolation of the Langmuir isotherm straight and is connected with Gibbs energy by the next relation

$\Delta G_{d}^{\circ}=-2.303 R T\left(\log _{10} 55.55+\log _{10} K_{d}\right)$

In this formula, $\mathrm{R}$ is the gas constant and 55.55 is the molar concentration of water.

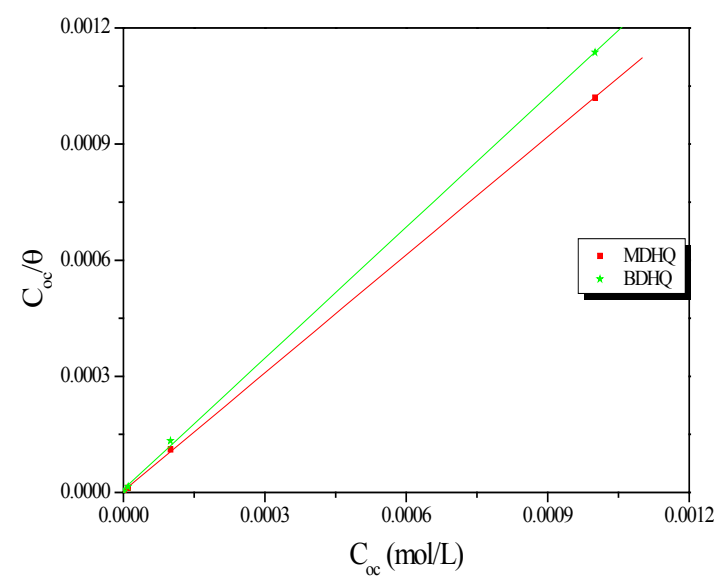

Fig. 1. Langmuir adsorption isotherm plots for both inhibitors on CS in aggressive media 
The following Table 2 summarizes the different thermodynamic parameters.

Table 2: Thermodynamic parameters for the adsorption of both inhibitors on $\mathrm{CS}$ in $\mathrm{HCl}$ electrolyte

\begin{tabular}{lccc}
\hline Inhibitors & $\mathrm{R}^{2}$ & $\mathrm{~K}_{\mathrm{d}}\left(\mathrm{L} \mathrm{mol}^{-1}\right)$ & $\Delta \mathrm{G}_{\mathrm{d}}\left(\mathrm{kJ} \mathrm{mol}^{-1}\right)$ \\
\hline $\mathrm{MDHQ}$ & 0.99997 & 270641.85 & -42.31 \\
$\mathrm{BDHQ}$ & 0.99988 & 125478.54 & -40.35 \\
\hline
\end{tabular}

The estimated $\Delta G^{\circ}$ values as depicted in Table 2 are lower than $-40 \mathrm{kJmol}^{-1}$ which means that the absorption process is of the chemisorption nature ${ }^{43}$.

\section{Potentiodynamic polarization curves}

Figures 2 illustrate the cathodic and anodic polarization curves of the $\mathrm{CS}$ in ${ }^{1} \mathrm{M} \mathrm{HCl}$ at room temperature, in the absence and in the presence of $\mathrm{BDHQ}$ and $\mathrm{MDHQ}$ at different concentrations. The curves were recorded after a holding time of the $\mathrm{CS}$ at the free corrosion potential for 30 minutes. According to these curves, I draw your attention to the facts that the addition of azomethine molecules involve a decrease both the cathodic and anodic current densities, this is more remarkable given at optimum concentration.

Diverse parameters derived from Tafel curves are arranged in Table 3. Concerning the inhibition efficiencies for each concentration of $\mathrm{BDHQ}$ and MDHQ were estimated by application of Eq. (14):

$$
\eta_{\text {Tafel }}=\left(1-\frac{i_{\text {inhb }}}{i_{\text {bleank }}}\right) \times 100
$$

Where $\mathrm{i}_{\text {blank }}$ and $\mathrm{i}_{\text {inhb }}$ are the corrosion current densities of blank and inhibited environment respectively.

As illustrated in Table 3, the increased of protective properties $\left(\eta_{\text {Tcfel }}\right)$ with inhibitors concentration indicates that the organic molecules works by blocking the active sites on $\mathrm{CS}^{44}$. However, displacement of the corrosion potential $\left(E_{c}\right)$ did not show any significant change in the field studied ( $\max \leq 18 \mathrm{mVvs}$. SCE) indicating that the MDHQ and $\mathrm{BDHQ}$ molecules are mixed type inhibitor ${ }^{45}$. In addition, the cathodic Tafel slopes $\left(\beta_{c}\right)$ varies with the synthesized azomethine derivatives addition suggesting a change of the mechanism of cathodic hydrogen evolution, exclusion of cathodic behavior as a result a formation a protective layer by BDHQ and MDHQ adsorbed. The existing values of the extracted anodic slopes $\left(\beta_{\mathrm{a}}\right)$ show a change with the addition of both inhibitors suggesting that the studied inhibitors was first adsorbed onto the metal surface and impeded by merely blocking the reaction sites of the working electrode surface without affecting the anodic reaction mechanism, in other words the existing of heteroatoms such as nitrogen and oxygen in synthesized molecules makes an important contribution for the formation of Fe-MDHQ and Fe-BDHQ complexes and participle in modification the dissolution reaction of $\mathrm{Fe}^{46}$. On the other hand, the dissolution rate of working electrode decrease after the addition of inhibitors throughout of potentials until $-250 \mathrm{mV} / \mathrm{SCE}$ and increases when the potential has become more anodic, this potential corresponding to desorption potential ${ }^{47}$. The effect of protection of $\mathrm{MDHQ}$ is higher than $\mathrm{BDHQ}$ which confirm the obtained data by gravimetric technique.
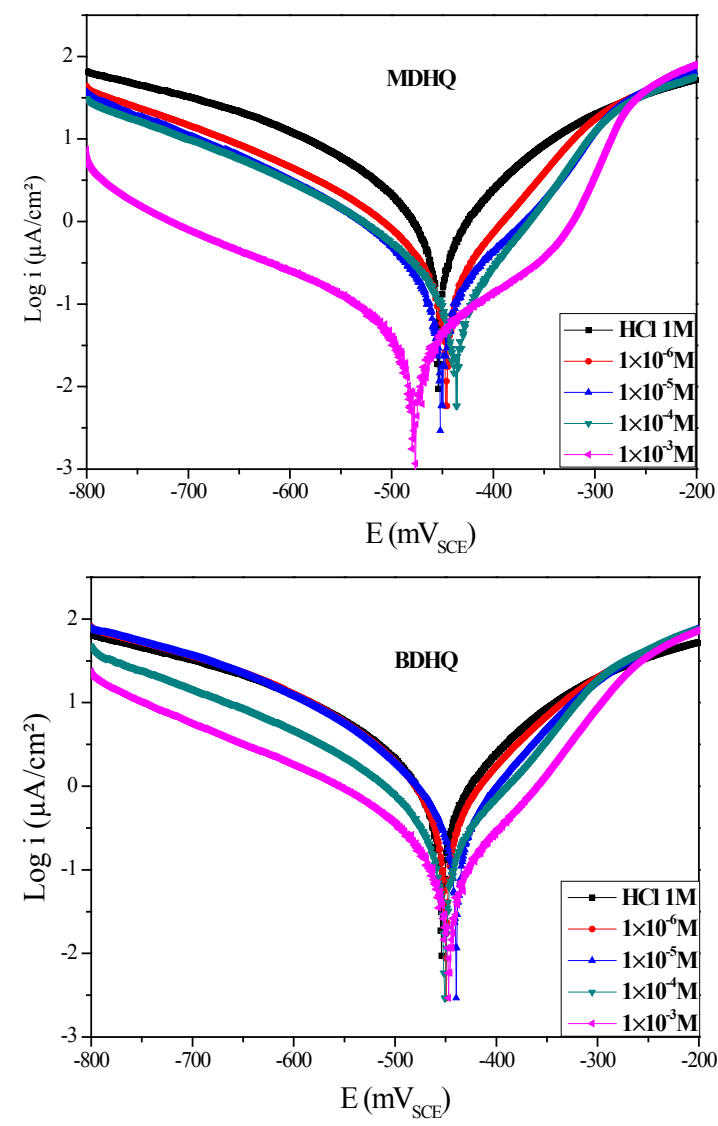

Fig. 2. Tafel curves for CS at $298 \mathrm{~K}$ in electrolyte in the absence and presence of synthesized azomethine derivatives 
Table 3: Diverse electrochemical parameters of $\mathrm{CS}$ in $1 \mathrm{M} \mathrm{HCl}$ in the absence and presence of synthesized azomethine derivatives

\begin{tabular}{lcccccc}
\hline Medium & {$[\mathrm{C}](\mathrm{mol} / \mathrm{L})$} & $-\mathrm{Ec}\left(\mathrm{mV}_{\mathrm{SCE}}\right)$ & $\mathrm{i}_{\text {corr }}\left(\mathrm{mA} / \mathrm{cm}^{2}\right)$ & $-\beta \mathrm{c}\left(\mathrm{mV} \mathrm{dec}^{-1}\right)$ & $\beta_{\mathrm{a}}\left(\mathrm{mV} \mathrm{dec}^{-1}\right)$ & $\eta_{\text {Tcfel }}(\%)$ \\
\hline $1 \mathrm{M}$ & 0.00 & 454 & 1.9477 & 182.9 & 151.8 & - \\
MDHQ & $10^{-3}$ & 478 & 0.0643 & 208.6 & 134.7 & 97 \\
& $10^{-4}$ & 437 & 0.3108 & 164.1 & 85.4 & 84 \\
& $10^{-5}$ & 452 & 0.4251 & 170.3 & 99.5 & 78 \\
& $10^{-6}$ & 446 & 0.7007 & 187.2 & 105.1 & 64 \\
$\mathrm{BDHQ}$ & $10^{-3}$ & 448 & 0.2646 & 184.9 & 91.2 & 86 \\
& $10^{-4}$ & 450 & 0.5307 & 95.2 & 89.4 & 73 \\
& $10^{-5}$ & 451 & 0.7374 & 187.2 & 107.8 & 62 \\
& $10^{-6}$ & 440 & 1.0879 & 151.9 & 114.6 & 44 \\
\hline
\end{tabular}

Electrochemical Impedance Spectroscopy (EIS)

The Nyquist curves in the presence and the absence of synthesized azomethine derivatives in $\mathrm{HCl}$ electrolyte are exhibited in Fig. 3. All the impedance spectra exhibit a single depressed semicircle. The diameter of semicircle increases with the increase of inhibitors concentrations. The semicircular appearance shows that the corrosion of carbon steel is controlled by the charge transfer, and the presence of BDHQ and MDHQ does not change the mechanism of carbon steel dissolution, in addition, these Nyquist diagrams are not perfect
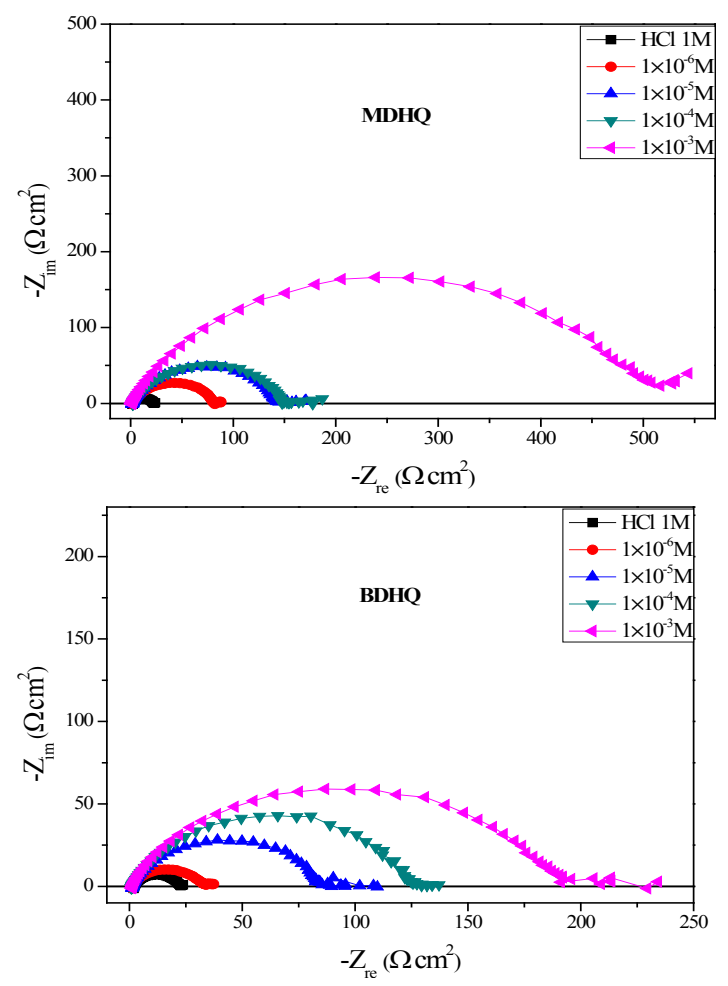

Fig. 3. Nyquist plot for CS in $1.0 \mathrm{M} \mathrm{HCl}$ electrolyte in absence and presence of azomethine molecules semicircles. The deviation of semicircles from perfect circular shape is often referred to as the frequency dispersion of interfacial impedance ${ }^{48}$.

Divers EIS parameters were achieved by the simulation of all impedance spectra through the appropriate equivalent circuit (Figure 4).

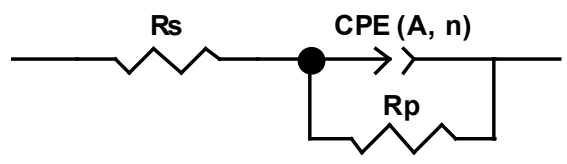

Fig. 4. The appropriate equivalent circuit used for fitting of all obtained impedance spectra

Our circuit comprising the following elements: the solution resistance (Rs), which is in series with a constant phase element (CPE) that is in parallel with the polarization resistance (Rp). So, the CPE defined the quasi-capacitive behaviour of the adsorbed chemical species in the electrical double layer and its use shows an improvement in fit in relation to the capacitance ${ }^{49}$. It is expressed by the next formula:

$Z_{\mathrm{CPE}}=A^{-1}(\mathrm{i} \omega)^{-n}$

Where $A$ is a constant of CPE in $\left(\Omega^{-1} \mathrm{~s}^{n}\right.$ $\left.\mathrm{cm}^{-2}\right), \mathrm{n}$ is a limited number from 0 to 1 identifying the phase shift and $\omega$ is a angular frequency in $\left(\mathrm{rad} \mathrm{s}^{-1}\right)$ which is calculated as the product of $2 \pi$ and the frequency.

All this has served to calculate the double layer capacitance $\left(\mathrm{C}_{\mathrm{dl}}\right)$ by next Eq.

$C_{\text {dl }}=\left(A R_{\mathrm{p}} 1-n\right)^{1 / n}$ 
The term of protection efficiency, $\eta \Omega(\%)$, is explicit via the last formula

$\eta_{\Omega}=\frac{R_{p m}-R_{p b}}{R_{p m}} \times 100$

In which $R_{p b}$ and $R_{p m}$ are the polarization resistance of working electrode in $\mathrm{HCl}$ electrolyte without and with azomethine molecules, respectively.

The use of equivalent circuit allows providing an excellent fit for all Nyquist spectra, the use of equivalent circuit allows to given an excellent fit for all Nyquist spectra and provide the values of simulated parameters in absence and presence of azomethine derivatives, these latter are presented in Table 4. It is worth mentioning that the values of $R_{p}$ of $M D H Q$ are superior that $B D H Q$, which is reflected that the performance of $\mathrm{MDHQ}$ is above that $\mathrm{BDHQ}$, the max performance are $97.2 \%$ and $90.8 \%$ for $\mathrm{MDHQ}$ and $\mathrm{BDHQ}$, respectively. however, the double layer capacitance typically exhibit variation opposite to that $R_{p}$, the rise of concentration in the case of two investigate molecules provoking fall in $\mathrm{C}_{d \|}$ values, It reached a minimum of 99.8 and $105.2\left(\mu \mathrm{F} \mathrm{cm}{ }^{-2}\right)$ in for $\mathrm{MDHQ}$ and $\mathrm{BDHQ}$ respectively in comparison with that obtained in electrolyte media (195.2 $\mu \mathrm{F}$ $\mathrm{cm}^{-2}$ ), which indicate that Schiff base acts as the primary interface inhibitor and the charge transfer controls the corrosion of steel under the open circuit conditions ${ }^{50}$. The increase of $n$ values $(0.86-0.76)$ Compared to the obtained values of blank solution $(0.75)$ is due to a reduction of surface heterogeneities as a result of the synthesized molecules adsorption on CS surface ${ }^{51}$.

Table 4: Impedance parameters for $\mathrm{CS}$ in $\mathrm{HCl}$ electrolyte with and without various concentrations of azomethine molecules

\begin{tabular}{lccrcccc}
\hline Medium & $\mathrm{C}(\mathrm{M})$ & $\mathrm{R}_{\mathrm{s}}\left(\Omega \mathrm{cm}^{2}\right)$ & \multicolumn{1}{c}{$\mathrm{R}_{\mathrm{p}}\left(\Omega \mathrm{cm}^{2}\right)$} & $10^{4} \mathrm{~A}\left(\Omega^{-1} \mathrm{~S}^{\mathrm{n}} \mathrm{cm}^{2}\right)$ & $\mathrm{n}$ & $\mathrm{C}_{\mathrm{dl}}\left(\mu \mathrm{F} \mathrm{cm} \mathrm{cm}^{-2}\right)$ & $\eta \Omega(\%)$ \\
\hline Blank & 1 & $2.04 \pm 0.05$ & $20.1 \pm 0.07$ & $4.36 \pm 0.33$ & $0.75 \pm 0.002$ & 193.7 & \\
MDHQ & $10^{-6}$ & $1.68 \pm 0.04$ & $78.3 \pm 0.04$ & $4.30 \pm 0.01$ & $0.78 \pm 0.003$ & 177.7 & 74.3 \\
& $10^{-5}$ & $1.63 \pm 0.05$ & $134.1 \pm 0.05$ & $4.21 \pm 0.02$ & $0.80 \pm 0.001$ & 159.1 & 85.0 \\
& $10^{-4}$ & $2.09 \pm 0.03$ & $136.7 \pm 0.08$ & $3.02 \pm 0.01$ & $0.82 \pm 0.002$ & 136.2 & 85.3 \\
& $10^{-3}$ & $0.32 \pm 0.04$ & $480.0 \pm 0.09$ & $0.18 \pm 0.03$ & $0.86 \pm 0.003$ & 99.6 & 95.8 \\
BDHQ & $10^{-6}$ & $1.45 \pm 0.05$ & $28.6 \pm 0.07$ & $7.41 \pm 0.08$ & $0.77 \pm 0.003$ & 190.1 & 29.2 \\
& $10^{-5}$ & $1.39 \pm 0.05$ & $77.9 \pm 0.01$ & $3.50 \pm 0.03$ & $0.80 \pm 0.002$ & 152.4 & 74.2 \\
& $10^{-4}$ & $1.16 \pm 0.04$ & $112.7 \pm 0.08$ & $4.19 \pm 0.02$ & $0.81 \pm 0.003$ & 129.3 & 82.2 \\
& $10^{-3}$ & $1.30 \pm 0.07$ & $177.5 \pm 0.03$ & $3.50 \pm 0.02$ & $0.84 \pm 0.001$ & 105.1 & 88.7 \\
\hline
\end{tabular}

\section{Effect of temperature}

The temperature present serious problems on the increases of corrosion rate, it would promote many changes at the level of working electrode surface such as ageing of metal, desorption of adsorbed molecule, dissolution of complexes formed and thermal decomposition of inhibitors.

In order to enlighten a little this effect, we examined the influence of temperature on the behaviour of the both MDHQ and $\mathrm{BDHQ}$ inhibitors at a controlled temperature of $298 \mathrm{~K}$ to $338 \mathrm{~K}$ by gravimetric experiments for $6 \mathrm{~h}$ of immersion. The results of this study are summarized in Table 5.

Intermediate results of $C_{R}$ values show that a regular growth with the temperature and very pronounced in electrolyte alone, results in a diminution of inhibitory efficacy of both azomethine molecules, which indicate that the equilibrium between adsorption and desorption processes is moved towards desorption process ${ }^{52}$. Generally, this behaviour is attributed to the physical adsorption nature, to confirm this type of adsorption to confirm this type of adsorption, it's required for using the kinetic models.

To estimated activation parameters of the corrosion reaction, Arrhenius Eq. ${ }^{53}$

$$
\begin{gathered}
\operatorname{Ln} C_{R}=\operatorname{Ln} K-\frac{E_{a}}{R T} \\
\text { Slope }=\left(-\frac{E_{a}}{R T}\right)
\end{gathered}
$$

Where $\mathrm{E}_{\mathrm{a}}, \mathrm{R}$ and $\mathrm{K}$, are apparent activation corrosion energy, gas constant and Arrhenius pre-exponential factor, respectively.

The variation of $\mathrm{Ln} C R$ as function of $1000 / T$ is establish in Fig. 5. Concerning the values 
of activation energy $\left(E_{a}\right)$ for the two Schiff's bases containing a 5-methyl-8-hydroxyquinoline motive are collected in Table 6.

The alternative formulation of transition sate equation is shown in equation ${ }^{54}$ :

$L n C_{R}=\operatorname{Ln} \frac{R T}{N h}+\frac{\Delta S_{a}}{R}-\frac{\Delta H_{a}}{R T}$

Slope $=\left(-\frac{\Delta H_{a}}{R}\right)$ and intercept $=\operatorname{Ln}\left(\frac{R}{N h}\right)+\frac{\Delta S_{a}}{R}$

Where $\mathrm{h}, \mathrm{N}, \Delta \mathrm{Sa}$ and $\Delta \mathrm{Ha}$ are plank's constant, Avogadro number, the entropy and enthalpy of activation, respectively. The change of $\mathrm{Ln} C R / T$ in relation to $1000 / \mathrm{T}$ graph are in Fig. 6 . The extracted $\Delta \mathrm{Ha}$ and $\Delta \mathrm{Sa}$ values are collected in Table 6.

Table 5: Corrosion parameters concluding from gravimetric experiments for $\mathrm{CS}$ in $\mathrm{HCl}$ electrolyte with and without both inhibitors in various temperatures

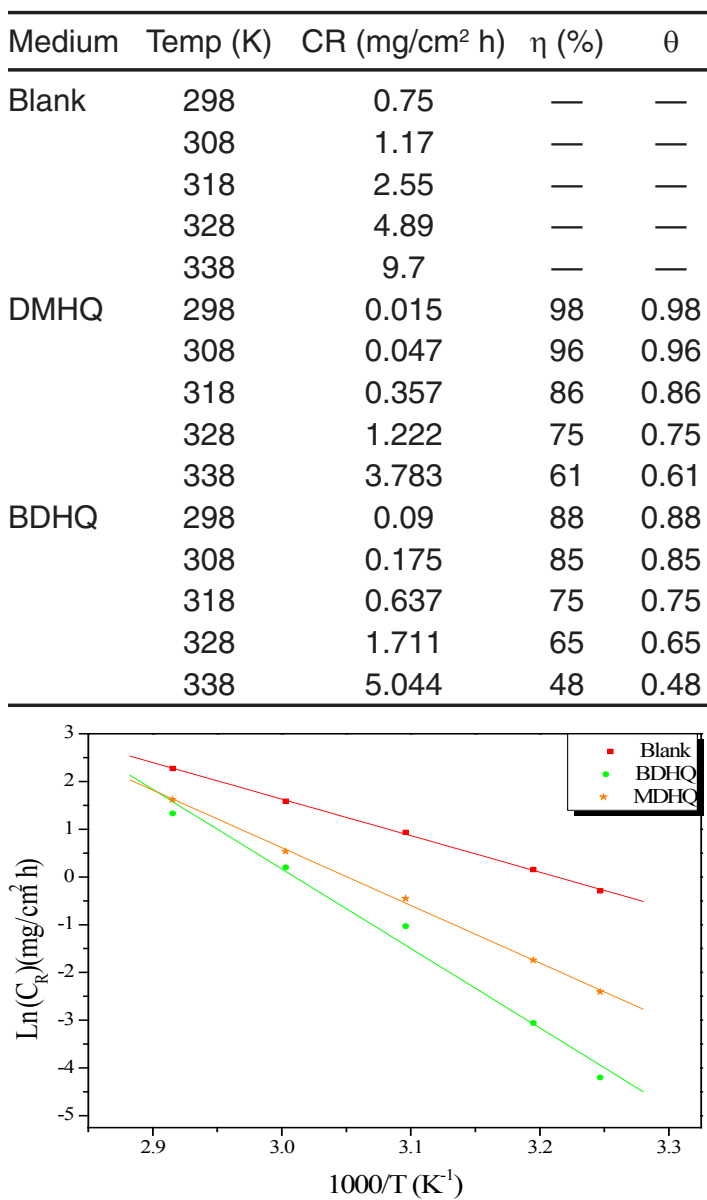

Fig. 5. Arrhenius graph for $\mathrm{CS}$ in $\mathrm{HCl}$ electrolyte with and without optimum concentration of both inhibitors at studied temperatures

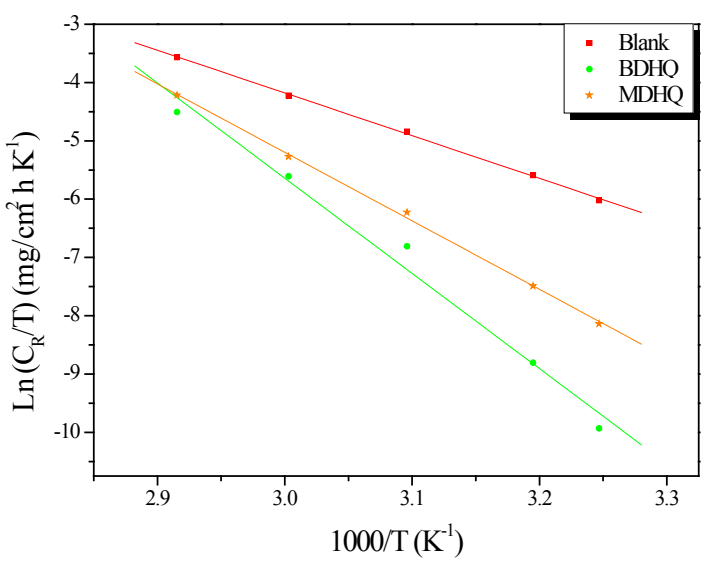

Fig. 6. Transition state graph for $\mathrm{CS}$ in $\mathrm{HCl}$ electrolyte with and without optimum concentration of both inhibitors at studied temperatures

Table 6: Kinetic parameters of corrosion for CS in $\mathrm{HCl}$ electrolyte with and without optimum concentration of both inhibitors at studied temperatures

\begin{tabular}{lccccc}
\hline Medium & $\mathrm{K}$ & $\mathrm{R}^{2}$ & $\begin{array}{c}\mathrm{Ea} \\
(\mathrm{kJ} / \mathrm{mol})\end{array}$ & $\begin{array}{c}\Delta \mathrm{H}_{\mathrm{a}} \\
(\mathrm{kJ} / \mathrm{mol})\end{array}$ & $\begin{array}{c}\Delta \mathrm{S}_{\mathrm{a}} \\
(\mathrm{J} / \mathrm{mol} \mathrm{K})\end{array}$ \\
\hline Blank & $4.74 \times 1010$ & 0.999 & 63.61 & 60.91 & -49.56 \\
DMHQ & $5.98 \times 1021$ & 0.993 & 138.49 & 135.80 & 162.94 \\
BDHQ & $5.95 \times 1015$ & 0.999 & 100.39 & 97.69 & 52.32 \\
\hline
\end{tabular}

The analysis of findings obtained involve that the enthalpies values for dissolution reaction of $\mathrm{CS}$ in ${ }^{1} \mathrm{M} \mathrm{HCl}$ in the presence two Schiff's bases containing a 5-methyl-8-hydroxyquinoline motive are superior than that of in $\mathrm{HCl}$ electrolyte. However, the CS dissolution process was defined as endothermic in nature due to the positive signs of $\Delta \mathrm{H}_{\mathrm{a}}$. The differentiation between physisorption and chemisorption stand on the obtained $\Delta \mathrm{H}_{\mathrm{a}}$ values and defined $a s^{55}$.

if $\Delta H_{a} \leq 40 \mathrm{KJ} / \mathrm{mol} \longrightarrow$ physisorption process while $\Delta H_{a} \geq 100 \mathrm{KJ} / \mathrm{mol} \longrightarrow$ chemisorption process

The estimated enthalpy value in case of $\mathrm{BDHQ}$ is near to $100 \mathrm{KJ} / \mathrm{mol}$ and that of MDHQ is superior to $100 \mathrm{KJ} / \mathrm{mol}$. So, the mode of adsorption of azomethine molecules is purely chemisorption.

The estimated $\mathrm{E}_{\mathrm{a}}$ in presence of synthesized compounds is exceeding than the analogous $\mathrm{E}_{\mathrm{a}}$ in their absence, the increase in temperature provoke la dissolution of chemical bonding and complexes formed between the molecules inhibitor and ions metallic and therefore release a greater surface 
exposed to the $\mathrm{HCl}$ electrolyte and therefore to an increase in the corrosion rate. The existing $E_{a}$ values are slightly up than the enthalpy values and the difference between them has not changed in all cases, suggesting that the corrosion process is a unimolecular reaction ${ }^{56}$; this is consonant with earlier results defined by following relation.

$$
R T=E_{a}-\Delta H_{a}=2.62 \mathrm{~kJ} \mathrm{~mol}^{-1}
$$

In view of the entropy results, the addition of BDHQ and MDHQ lead to positive value of entropy, where as a negative value is observed in blank solution, this augmentation is resulting from the rise in disorder when the reactants are transformed to the complexes. These results could also be explained by the substitution process of water molecules throughout adsorption of azomethine molecules on the electrode surface and consequently the increasing in $\Delta \mathrm{S}_{\mathrm{a}}$ was assigned to the rise in solvent entropy ${ }^{57}$.

\section{Quantum chemical calculations}

As has been proved experimentally that our compounds are good inhibitors against corrosion, and the inhibitory performance of MDHQ is better than BDHQ. To confirm this result, we will do the theoretical calculation using the DFT theory, for this purpose, the global reactivity will be determined by the quantum chemical descriptors and the local reactivity will be the determined via local indices (Fukui indices). All this shows that the structural properties of the molecules studied are proportional with their inhibitory efficiencies.

\section{Global reactivity of BDHQ and MDHQ compounds}

For more interpretation and understanding the phenomena that are established in the studies of corrosion inhibitions, we performed a chemical quantum theoretical calculation using density functional theory (DFT) at B3LYP functional ${ }^{58}$. The global reactivity of a molecule is characterized by the frontier molecular orbitals (FMO) such as the HOMO is exterior most occupied orbital which owns the highest energy level, so it behaves as an available orbital to give electron ${ }^{28}$. While, the LUMO is inside most unoccupied orbital which is available to accept electrons $\mathbf{s}^{59}$. The optimized structures in the most stable state and the density distribution of FMO orbital's for molecules BDHQ and MDHQ for the $6-31++G(d, p)$ are shown in Fig. 7. The graphical images of the HOMO and LUMO of the two species $\mathrm{BDHQ}$ and $\mathrm{MDHQ}$ (Fig.7) show that the location of the electron density HOMO and LUMO is distributed on the $\pi$ electrons $\left(\mathrm{sp}^{2}\right)$ to the aromatic rings and the free doublets of the nitrogen atoms $\mathrm{N}$ in the planar structure of hydroxyquinoline for two studied compounds.

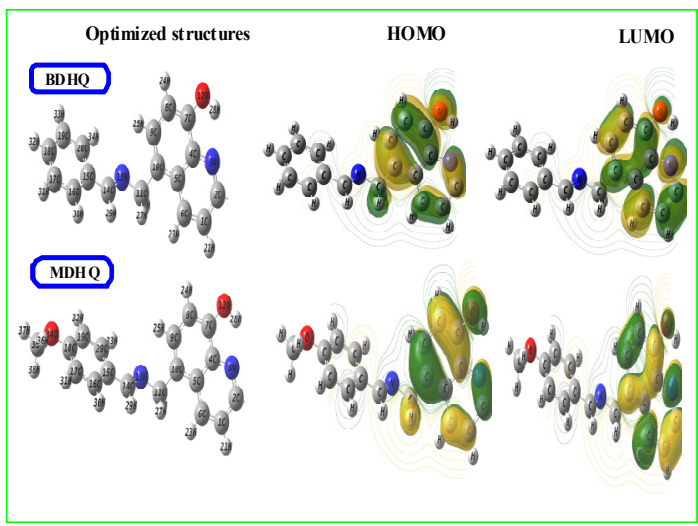

Fig. 7. Optimized structures and frontier molecule orbital density distributions of the inhibitors BDHQ and MDHQ

Selected main quantum chemical descriptors (QCP) for the neutral forms of the inhibitors BDHQ and MDHQ are grouped in Table 7. It is indisputable that the best inhibitors are electron donors of electrons to another element that contains unoccupied orbitals available to accept electrons. According to Table 7 it is apparent that the inhibitor molecule MDHQ has high values of EHOMO $(-5.447 \mathrm{eV})$ and $\Delta \mathrm{N}_{110}(0.345)$ which indicates that the performance of transmission of electrons is high in $\mathrm{MDHQ}$ than $\mathrm{BDHQ}$. Likewise, the inhibitor MDHQ showed the lowest $\triangle \mathrm{E}(4.044 \mathrm{eV})$, lowest ELUMO $(-1.403 \mathrm{eV})$, lowest $\eta(2.022 \mathrm{eV})$ and $\chi(3.425 \mathrm{eV})$, All of these descriptors suggest better stability and more interaction. This supports the experimental results that say that $\mathrm{BDHQ}$ inhibitor has a great inhibitory performance compared to the MDHQ inhibitor. With regard to the influence of the dipole moment on the molecular reactivity for two inhibitors tested. Turning to the study of literature, the trend of the dipole moments $\mu(D)$ of the compounds indicates that the inhibitory efficacy increases with the $\mu$ (D) of the molecule. Then the high value of the dipole moment strengthens the dipole-dipole form of the interactions between the inhibitory molecule and the metal surface ${ }^{60}$. This reflects that the adsorption performance of an inhibitor is high. In this context, the values of the dipole moment are also gathered in the Table 7, it is remarkable that the high value of the $\mu(5.015 \mathrm{D})$ of the inhibitor MDHQ suggests that this inhibitor adsorbs better than the inhibitor BDHQ (3.620D) on the metal surface. 
Table 7: QCPs for two inhibitors BDHQ and MDHQ calculated with the DFT/B3LYP/6-311++G method in the gaseous phase

\begin{tabular}{lccccccc}
\hline Compounds & $\mathrm{E}_{\text {номо }}(\mathrm{eV})$ & $\mathrm{E}_{\text {LUMO }}(\mathrm{eV})$ & $\Delta \mathrm{E}_{\text {gap }}(\mathrm{eV})$ & $\eta_{\text {inh }}(\mathrm{eV})$ & $\chi_{\text {inh }}(\mathrm{eV})$ & $\Delta \mathrm{N}_{110}$ & $\mu(\mathrm{D})$ \\
\hline $\mathrm{BDHQ}$ & -5.514 & -1.345 & 4.169 & 2.0845 & 3.4295 & 0.334 & 3.620 \\
$\mathrm{MDHQ}$ & -5.447 & -1.403 & 4.044 & 2.022 & 3.425 & 0.345 & 5.015 \\
\hline
\end{tabular}

In objective to characterize the mechanism of adsorption of organic molecules in hydrochloric acid, we are interested in the protonation of these molecules to see their reactivity. The same trend has been noticed by using the protonation of the studied molecules. From the results obtained by our theoretical calculations of the protonated molecules. Table 8 summarizes the calculated chemical descriptors of our protonated compounds in nitrogen atom $\mathrm{N} 13$ which is the most available site for protonation. First of all, we observe a remarkable shift in the values of the quantum parameters of protonated molecules BDHQ and MDHQ and especially in the values of $\mathrm{E}_{\text {номо }}, \mathrm{E}_{\text {Lumo }}$, and $\Delta \mathrm{N}_{110}$ that move to more negative values ${ }^{61}$. This indicates that the responsiveness of our products changes appropriately and these molecules become more reactive according their protonation. This observation can be confirmed by the high values of the dipole moment of protonated inhibitors BDHQ (9.547D) and MDHQ (9.725D). Indeed, this shows that electrostatic interactions have been established between our protonated products and the surface of the substrate.

All calculated and measured values of quantum chemical descriptors indicate that the order of inhibition efficiency is MDHQ > BDHQ, this is in good agreement with the experimental results. This method will be very effective towards prediction of inhibition phenomenon of a series of unknown inhibitors, also, we can use this technical to synthesize new molecules more adequate and effective against corrosion.

Table 8: QCPs for two inhibitors BDHQ and MDHQ protonated calculated with the DFT/B3LYP/6$311++G$ method in the gaseous phase

\begin{tabular}{lccccccc}
\hline Compounds & $\mathrm{E}_{\text {номо }}(\mathrm{eV})$ & $\mathrm{E}_{\text {Luмо }}(\mathrm{eV})$ & $\Delta \mathrm{E}_{\text {gap }}(\mathrm{eV})$ & $\eta_{\text {inh }}(\mathrm{eV})$ & $\chi_{\text {inh }}(\mathrm{eV})$ & $\Delta \mathrm{N}_{110}$ & $\mu(\mathrm{D})$ \\
$\mathrm{BDHQ}$ & -8.746 & -6.460 & 2.286 & 1.143 & 7.603 & -1.217 & 9.547 \\
$\mathrm{MDHQ}$ & -8.544 & -6.995 & 1.549 & 0.774 & 7.769 & -1.904 & 9.725 \\
\hline
\end{tabular}

Local reactivity of BDHQ and MDHQ compounds

One of the most frequent local descriptors for studding local reactivity on a molecule is the Fukui indices. We based on the location of the nucleophilic and electrophilic centers of each atom in a compound ${ }^{62}$.

It is indisputable that a molecule that has many of the atoms with high values of the $f_{i}(\vec{r})^{+}$ and $f_{i}(\vec{r})^{-}$functions, it has a great chance to adsorb on the surface of the substrate and considered a good inhibitor of corrosion. The values of the Fukui functions $f_{i}(\vec{r})^{+}$and $f_{i}(\vec{r})^{-}$of our neutral compounds are listed in Table 9. The analysis of the results obtained in this table thus confirms the previous results and show that the nitrogen atom $\mathrm{N} 13$ is considered as the favorable site for protonation. Indeed, the atom $\mathrm{N} 13$ has the largest value of $f_{i}(\vec{r})^{-}$such as 0.061 and 0.097 for BDHQ and MDHQ compounds, respectively, and it remains the appropriate center of the proton attack $\left(\mathrm{H}^{+}\right)$. In addition, it is clear that the MDHQ compound has several disoponible active sites to give electrons with a high density of $f_{i}(\vec{r})^{-}$, we quote the atoms $\mathrm{C}(2), \mathrm{N}(3), \mathrm{C}(6), \mathrm{C}(7), \mathrm{C}(10), \mathrm{O}(12)$ and $\mathrm{N}(13)$. These atoms have enriched the molecular structure of MDHQ for well adsorbed on the surface of metal containing electropositive centers.

\section{Study of the inhibitor / metal interaction by the Monte Carlo method}

The complexity of the corrosion protection system requires knowing several factors involved in this operation, as the adsorption $\left(E_{\text {ads }}\right)$ or interaction $\left(E_{\text {int }}\right)$ energy such as $\left(E_{\text {ads }}=-E_{\text {int }}\right)$ between the elements of the studied system ${ }^{63}$.

Figure 8 shows the most stable configuration of interaction of our compounds and substrate of the iron surface. As can be seen in Fig. 8, It is quite clear that both compounds of $B D H Q$ and $M D H Q$ quinoline 
derivatives take a location just above on the surface of iron (110). In addition, structures were adsorbed on Fe (110) surface in a parallel way and especially by the aromatic heterocycles of 8-hydroxyquinoline. Which means that these compounds have active site that interacts with the surface of Fe (110).

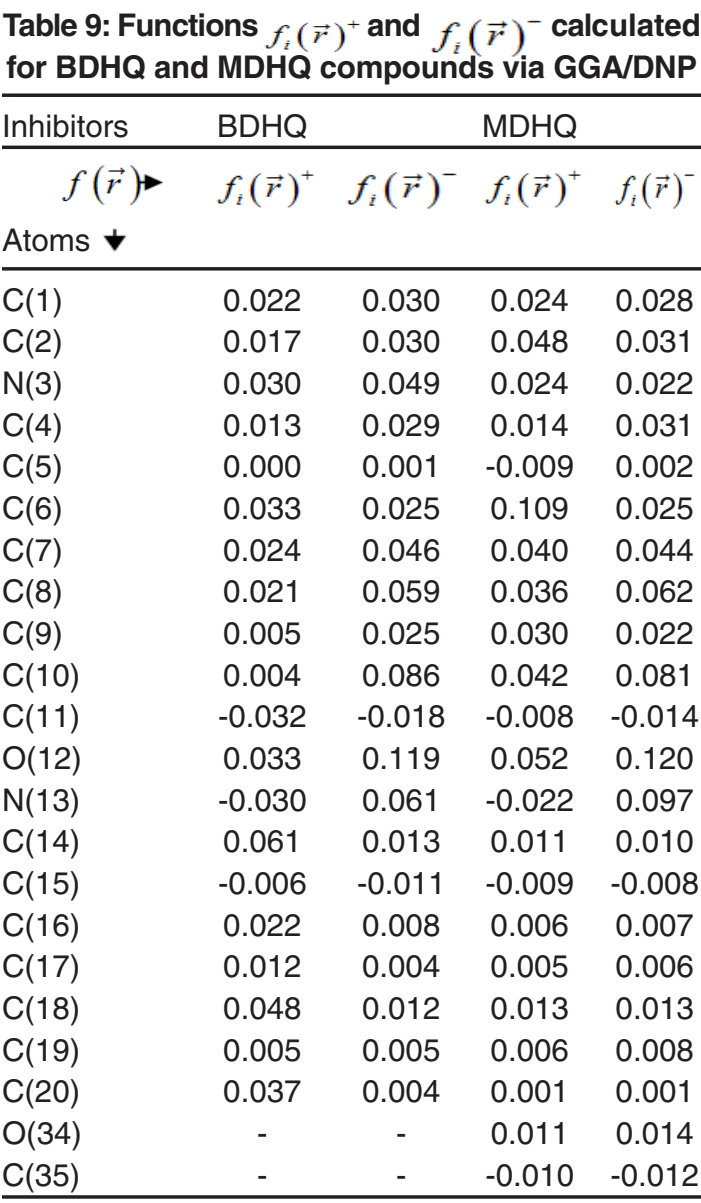

A quantitative vision through the energy aspect has been calculated namely the total energy $\left(E_{\text {tot }}\right)$, the adsorption $\left(E_{\text {ads }}\right)$ or interaction $\left(E_{\text {int }}\right)$ energy $\left(E_{\text {ads }}=-E_{\text {int }}\right)$, the reports of energies for the components of the system being studied ( $\mathrm{dE}_{\text {ads }} /$ $\mathrm{dNi}$ ). When the system studied in equilibrium can be represented all the values energies $\left(E_{t o t}, E_{a d s}, E_{i n t}\right.$ and $\mathrm{dE}_{\mathrm{ads}} / \mathrm{dNi}$ in Table 10. According to the analysis the data of the results obtained in this Table, it may be noted that Eads energy values are negative. That shows that the adsorption process is exothermic nature ${ }^{64}$. We found same remark concerning $E_{\text {tot }}$ values. Which indicate the adsorption could occur spontaneously ${ }^{64}$. As has been noticed that, The $E_{\text {ads }}$ value of the compound (MDHQ) $\left(E_{i n t}=\right.$ $5740.345 \mathrm{Kcal} / \mathrm{mol}$ ) is bigger that of the inhibitor

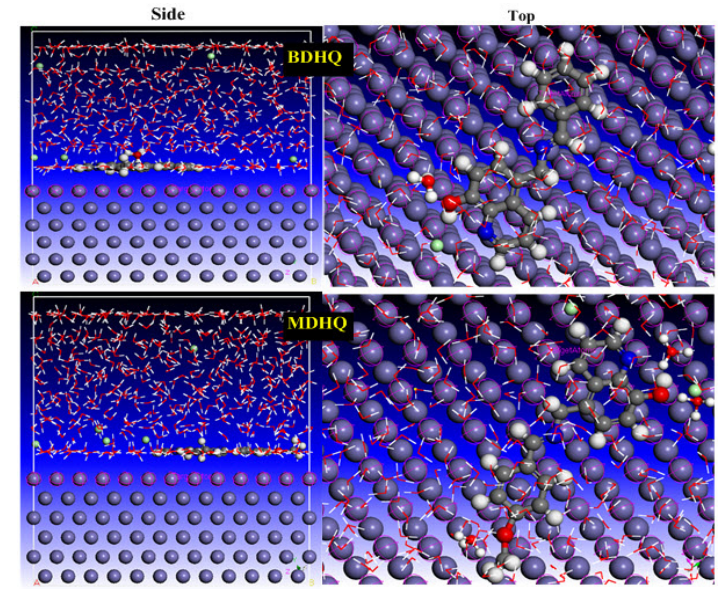

Fig. 8. The spatial topology of the best adsorption configuration of the $B D H Q$ and $M D H Q$ on the $\mathrm{Fe}$ (110) surface in acidic solution

$(B D H Q)\left(E_{\text {int }}=5523.257 \mathrm{Kcal} / \mathrm{mol}\right)$, which means that adsorption of MDHQ molecule on Fe (110) surface in the aggressive medium studied is stronger than $\mathrm{BDHQ}$. These results allow us to conclude that there is a good agreement between the practical studies and the data obtained by the Monte Carlo simulations.

\section{CONCLUSION}

Two selected Azomethine derivatives have been synthesized and characterized NMR and elementary analyzes. BDHQ and MDHQ were evaluated using both practical and theoretical approaches for their anticorrosion properties of carbon steel in $\mathrm{HCl}$ electrolyte. The main results achieved afford to draw the next conclusions:

The azomethine molecules BDHQ and $\mathrm{MDHQ}$ act as excellent inhibitors for CS in $\mathrm{HCl}$ electrolyte and their inhibition efficiency obtained by Tafel polarization reached 97 and $86 \%$ for $\mathrm{MDHQ}$ and $\mathrm{BDHQ}$ respectively at optimum concentration, the inhibition efficiencies estimated by gravimetric and electrochemical methods are in reasonable agreement.

- $\quad$ The nature of radical on para of phenyl linked to aldimines function improve the inhibitory activity of studied azomethine.

- The adsorption of BDHQ and MDHQ on working electrode obeys Langmuir adsorption isotherm with a chemisorption mechanism. The overall reactivity of the inhibitors tested 
has been discussed by quantum chemical descriptors.

- $\quad$ The protonation of our compounds shows that the reactivity of these inhibitors becomes more important.

- The local reactivity of the BDHQ and MDHQ molecules shows that these inhibitors contain several reactive sites responsible for the adsorbate / substrate interactions.
Monte Carlo simulations show that compound MDHQ adsorbs better than compound $B D H Q$.

\section{ACKNOWLEDGMENT}

The authors wish to thank the "Moroccan Ministry of Higher Education" for providing all the facilities and for supporting this work.

\section{REFERENCES}

1. Corradi, M.; Di Schino, A.; Borri, A.; Rufini, R.; Constr. Build. Mater., 2018, 181, 335-346.

2. Brenna, A.; Beretta, S.; Uglietti, R.; Lazzari, L.; Pedeferri, M.; Ormellese, M.; Corros. Eng. Sci. Techn., 2017, 52(4), 253-260.

3. Qiu, S.; Chen, C.; Zheng, W.; Li, W.; Zhao, H.; Wang, L.; Synth. Met., 2017, 229, 39-46.

4. Zarrouk, A.; Zarrok, H.; Salghi, R.; Touir, R.; Hammouti, B.; Benchat, N.; Afrine, L.L.; Hannache, H.; El Hezzat, M.; Bouachrine, M.; J. Chem. Pharm. Res., 2013, 5(12), 1482-1491.

5. Salhi, A., Tighadouini, S., El-Massaoudi, M., Elbelghiti, M., Bouyanzer, A., Radi, S., Zarrouk, A.; J. Mol. Liq., 2017, 248, 340-349.

6. Zarrok, H.; Zarrouk, A.; Salghi, R.; Ebn Touhami, M.; Oudda, H.; Hammouti, B.; Touir, R.; Bentiss, F.; Al-Deyab, S.S.; Int. J. Electrochem. Sci., 2013, 8, 6014-6032.

7. Zarrok, H.; Salghi, R.; Zarrouk, A.; Hammouti, B.; Oudda, H.; Bazzi, Lh.; Bammou, L.; Al-Deyab, S.S.; Der Pharma Chem., 2012, 4(1), 407-416.

8. Gattinoni, C.; Michaelides, A.; Farad. Disc., 2015, 180, 439-458.

9. Abdallah, M.; Eltass, H.M.; Hegazy, M.A.; Ahmed, H.; Prot. Met. Phys. Chem. Surf., 2016, 52(4), 721-730.

10. Costantino, G.; Future Med. Chem., 2014, 6(8), 841-843.

11. Ramann, G.A.; Cowen, B. J.; Tetrahedron Lett., 2015, 56(46), 6436-6439.

12. El Faydy, M.; Djassinra, T.; Haida, S.; Rbaa, M.; Ounine, K.; Kribii, A.; Lakhrissi, B.; J. Mater. Environ. Sci., 2017, 8(11),3855-3863.

13. Oliveri, V.; Vecchio, G.; Eur. J. Med. Chem., 2016, 120, 252-274.

14. Gawne, P.; Man, F.; Fonslet, J.; Radia, R.; Bordoloi, J.; Cleveland, M.; de Rosales, R.T.; Dalton Trans., 2018, 47, 9283-9293.

15. Gerengi, H.; Mielniczek, M.; Gece, G.;
Solomon, M.M.; Ind. Eng. Chem. Res., 2016, 55(36), 9614-9624.

16. El faydy, M.; Touir, R.; Ebntouhami, M.; Zarrouk, A.; Jama, C.; Lakhrissi, B.; Bentiss, F.; Phys. Chem. Chem. Phys., 2018, 20, 20167-20187.

17. Tian, Z.; Shi, H.; Liu, F.; Xu, S.; Han, E.H.; Prog. Org. Coat., 2015, 82, 81-90.

18. Aly, M.R.E.S.; Shokry, H.; Sharshar, T.; Amin, M.A.; J. Mol. Liq., 2016, 214, 319-334.

19. Liu, W.; Singh, A.; Lin, Y.; Ebenso, E.E.; Zhou, L.; Huang, B.; Int. J. Electrochem. Sci., 2014, 9(10), 5574-5584.

20. Obot, I.B.; Ankah, N.K.; Sorour, A.A.; Gasem, Z.M.; Haruna, K.; Sustainable Mater. Technol., 2017, 14, 1-10.

21. El Faydy, M.; Galai, M.; Touhami, M.E.; Obot, I.B.; Lakhrissi, B.; Zarrouk, A.; J. Mol. Liq., 2017, 248, 1014-1027.

22. Alaghaz, A.N.M.; Zayed, M.E.; Alharbi, S.A.; Ammar, R. A.; Chinnathambi, A.; J. Mol. Struct., 2015, 1087, 60-67.

23. Jafari, H.; Akbarzade, K.; Effect of concentration and temperature on carbon steel corrosion inhibition, Journal of Bio-and Tribo-Corrosion., 2017, 3, 8-14.

24. Sılku, P.; Özkınalı, S.; Öztürk, Z.; Asan, A.; Köse, D.A.; J. Mol. Struct., 2016, 1116, $72-83$.

25. El Faydy, M.; Galai, M.; El Assyry, A.; Tazouti, A.; Touir, R.; Lakhrissi, B.; Zarrouk, A.; J. Mol. Liq., 2016, 219, 396-404.

26. Standard, A.S.T.M.; G1-03, Standard practice for preparing, cleaning, and evaluating corrosion test specimens, Annual Book of ASTM Standards., 2003, 3, 17-25.

27. Frisch, M.J.; Trucks, G.W.; Schlegel, H.B.; Scuseria, G.E.; Gaussian 09, Revision A.01, Gaussian, Inc., Wallingford CT., 2009.

28. Zhang, J.; Liu, Z.; Han, G.C.; Chen, S.L.; Chen, Z.; Appl. Surf. Sci., 2016, 389, 601-608. 
29. Olasunkanmi, L.O.; Kabanda, M.M.; Ebenso, E.E.; Physica ELow Dimens. Syst. Nanostruct., 2016, 76, 109-126.

30. Olasunkanmi, L.O.; Obot, I.B.; Kabanda, M.M.; Ebenso, E.E.; J. Phys. Chem. C., 2015 119, 16004-16019.

31. Pearson. R.G.; Inorg. Chem., 1988, 27, 734-740.

32. Sastri, V.; Perumareddi, J.; Corros., 1997, 53, 617-622.

33. Cao, Z.; Tang, Y.; Cang, H.; Xu, J.; Lu, G.; Jing, W.; Corros. Sci., 2014, 83, 292-298.

34. Olasunkanmi, L.O., Obot, I.B., Ebenso, E.E.; RSC Adv., 2016, 6, 86782-86797.

35. Belghiti, M.E.; Karzazi, Y.; Dafali, A.; Obot, I.B.; Ebenso, E.E.; Emrane, K.M.; Bahadur, I.; Hammouti, B.; Bentiss, F.; J. Mol. Liq., 2016, 216, 874-886.

36. Nabah,R.; Benhiba, F.; Ramli,Y.; Ouakki, M.; Cherkaoui, M.; Oudda, H.; Touir, R.; Warad, I.; Zarrouk, A.; Anal. Bioanal. Electrochem., 2018, 10, 1375-1398.

37. Sun,H.; Ren, P.; Fried, J.R.; Comput. Theor. Polym. Sci., 1998, 8, 229-246.

38. Zarrouk, A.; Hammouti, B.; Lakhlifi, T.; Traisnel, M.; Vezin, H.; Bentiss, F.; Corros. Sci., 2015, 90, 572-584.

39. Zarrouk, A.; Zarrok, H.; Ramli, Y.; Bouachrine, M.; Hammouti, B.; Sahibed-dine, A.; Bentiss, F.; J. Mol. Liq., 2016, 222, 239-252.

40. Tourabi, M.; Nohair, K.; Nyassi, A.; Hammouti, B.; Jama, C.; Bentiss, F.; J. Mater. Environ. Sci., 2014, 5(4), 1133-1143.

41. Mehdaoui, R.; Khelifa, A.; Khadraoui, A.; Aaboubi, O.; Ziane, A.H.; Bentiss, F.; Zarrouk, A.; Res. Chem. Intermed., 2016, 42(6), 5509-5526.

42. Kaddouri, Y.; Takfaoui, A.; Lamsayah, M.; El Azzouzi, M.; Boyaala, R.; Chetouani, A.; Touzani, R.; Mor. J. Chem., 2017, 5(3), 5-3.

43. Tayebi, H.; Bourazmi, H.; Himmi, B.; El Assyry, A.; Ramli, Y.; Zarrouk, A.; Geunbour, A.; Hammouti, B.; Der Pharma Chem., 2014, 6(5), 220-234.

44. Ahmed, M.H.O.; Al-Amiery, A.A.; Al-Majedy, Y.K.; Kadhum, A.A.H.; Mohamad, A.B.; Gaaz, T.S.; Results Phys., 2018, 8, 728-733.

45. Obot, I.B.; Onyeachu, I.B.; Umoren, S.A.; Journal of Bio-and Tribo-Corrosion., 2018, 4(2), 18-35.
46. Jafari, H.; Danaee, I.; Eskandari, H.; RashvandAvei, M.; Ind. Eng. Chem. Res., 2013, 52, 6617-6632.

47. Debab, H.; Douadi, T.; Daoud, D.; Issaadi, S.; Chafaa, S.; Int. J. Electrochem. Sci., 2018, 13, 6958-6977.

48. Jafari, H.;Danaee, l.;Eskandari, H.;Rashvand Avei, M.; J. Mater. Sci. Technol., 2014, 40, 239-252.

49. Jafari, H.; Danaee, I.; Eskandari, H.; Rashvand Avei, M.; J. Environment. Sci. Health, Part A., 2013, 48, 1628-1641.

50. Kuriakose, N.; Thomas, K.; Raphael, V.; Varghese, C.; Current Chemistry Letters., 2017, 6(4), 177-186.

51. Mohsenifar, F.; Jafari, H.; Sayin, K.; Journal of Bio-and Tribo-Corrosion., 2016, 2, 1.

52. Tourabi, M.; Sahibed-Dine, A.; Zarrouk, A.; Obot, I. B.; Hammouti, B.; Bentiss, F.; Nahlé, A.; Prot. Met. Phys. Chem. Surf.m, 2017, 53(3), 548-559.

53. Jafari, H.; Sayin, K.; Trans. Indian Inst. Met., 2016, 69, 805-815.

54. Mourya, P.; Banerjee, S.; Rastogi, R.B.; Singh, M.M.; Ind. Eng. Chem. Res., 2013, 52(36), 12733-12747.

55. Hamdy, A.; El-Gendy, N.S.; Egypt. J. Pet., 2013, 22(1), 17-25.

56. Jafari, H.; Sayin, K.; J. Taiwan Inst. Chem. Eng., 2015, 56, 181-190.

57. Benhiba, F.; Zarrok, H.; Elmidaoui, A.; El Hezzat M.; Touir, R.; Guenbour, A.; Zarrouk, A.; Boukhris, S.; Ouddaa, H.; J. Mater. Environ. Sci., 2015, 6(8), 2301-2314.

58. C. Verma,C.; Quraishi, M.A.; Olasunkanmi, L.O.; Ebenso, E.E.; RSC Adv., 2015, 5, 85417-85430.

59. Hu, S.Q.; Hu, J.Q.; Fan, C.C.; Jia, X.L.; Zhang, J.; Guo, W.Y.; Acta Chim. Sin., 2010, 68, 2051-2058.

60. Obot, I.; Obi-Egbedi, N.; Ebenso, E.E.; Afolabi, A.; Oguzie, E.; Res. Chem. Intermed., 2013, 39, 1927-1948.

61. Kovacevic, N.; Kokalj, A.; Corros. Sci., 2011, 53, 909-921.

62. Kokalj, A.; Chem. Phys., 2012, 393, 1-12.

63. Ryu, D.Y.; Free, M.L.; Anti-Corros. Method. M., 2006, 53, 12-18.

64. Kabanda, M.M.; obot, I.B.; Ebenso, E.E.; Int. J. Electrochem. Sci., 2013, 8, 10839-10850. 